Research Article

\title{
Surface Settlement Analysis Induced by Shield Tunneling Construction in the Loess Region
}

\author{
Caihui Zhu (iD) ${ }^{1,2,3}$ \\ ${ }^{1}$ State Key Laboratory of Eco-hydraulics in Northwest Arid Region, Xi'an University of Technology, Xi'an, Shaanxi 710048, China \\ ${ }^{2}$ Institute of Geotechnical Engineering, Xi'an University of Technology, 5 South Jinhua Road, Xi'an, Shaanxi 710048, China \\ ${ }^{3}$ Shaanxi Provincial Key Laboratory of Loess Mechanics, Xi'an University of Technology, Xi'an, Shaanxi 710048, China
}

Correspondence should be addressed to Caihui Zhu; zhucaihui123@163.com

Received 19 January 2021; Revised 8 February 2021; Accepted 27 February 2021; Published 12 March 2021

Academic Editor: Xiangtian Xu

Copyright ( 92021 Caihui Zhu. This is an open access article distributed under the Creative Commons Attribution License, which permits unrestricted use, distribution, and reproduction in any medium, provided the original work is properly cited.

\begin{abstract}
The influence and prediction of shield tunneling construction on surface settlement (SS) and adjacent buildings is a hot topic in underground space engineering. In this work, several analytical methods are utilized to estimate the maximum surface settlement (MSS) and conduct a parametric sensitivity analysis based on Xi'an Metro line 2. The results show that there are mainly nine factors influencing the SS induced by shield tunneling construction in loess strata. The disturbance degree of the surrounding soil during the shield advancing stage has the largest influence on the SS, followed by the seepage of the shield lining segments or falling water levels, which lead to the overlying soil consolidation. After this is the grouting filling effect at the shield tail, followed by the reinforcement effect of the tunnel foundation and the track. The smallest influencing factors on the SS are the shield overexcavation and improper shield attitudes during the construction period. The sensitivity analysis results of the above influencing factors may offer a scientific guidance for the control of shield tunneling construction.
\end{abstract}

\section{Introduction}

In the Xi' an loess strata, more than 20 subway lines are under construction or being designed. The subways are constructed with the shield tunneling method, and these subways cross beneath ancient sites, architectural structures, ground fissures, underground pipelines (e.g., water and natural gas), and other buildings. Through long-term investigations of the existing subway lines constructed in loess strata, serious issues with the tunnels and subway stations have been reported, such as the uneven deformation of lining segments, soil strata, and pavements; lining seepage; underground pipeline ruptures; and tilting of buildings and foundations. These issues greatly influence the surface settlement (SS) and the structural integrity of adjacent structures. The SS induced by shield construction can be classified into two categories. In the first category, the SS is caused by the improper control of the shield excavation during the construction period. In the second category, the SS occurs during the postconstruction period because of changes in the mechanical properties of the soil around the tunnel. Controlling and forecasting the SS during shield tunneling are the most important geotechnical engineering problem to be solved. A number of analytic methods have been proposed and widely used to predict the SS in the engineering practice [1-11].

In previous research results, there are many analytical estimation methods to predict the SS induced by tunneling construction. The displacement-controlled boundary around the tunnel opening has usually been expressed as different convergence modes in the reported methods, such as the point source theory $[1-3,12]$, the complex variable theory $[4,5,13-16]$, the stress function elastic theory $[6,7,17,18]$, and the stochastic medium method $[8,9]$. Huang and Zeng [10] proposed the uniform convergence model and the analytical solution of the stratum displacement for the double-circle shield tunnel. Based on the elastic solutions of Lame and Kiersch, Liu and Zhang [19] also proposed an analytical solution of the SS caused by tunnel excavation under the condition of plane strain and 
nonuniform stress field. Lu et al. [20] proposed a unified displacement function of the cross section of a circular shallow tunnel under complex geological and construction conditions. This function is expressed by a Fourier series and can reflect the horizontal and vertical asymmetrical deformation behaviors of the tunnel cross section. Shen and Zhu [21] proposed an analytical method using the virtual image technique and Fourier transform solutions to estimate the ground SS caused by the tail void grouting pressure in shield tunnel construction. Fang et al. [22] reported that a normal probability function can be extended to estimate the SS due to shield tunneling, which can consider various types of shield machines, depths, and diameters. Zhang et al. [11] presented an analytical solution by the complex variable method to predict the soil deformation due to tunneling in clay; this approach considers the linear stiffness influence and the nonuniform convergence boundary condition.

The analytical methods that are described above systematically consider the stratum conditions and the shield construction technologies. However, when predicting the SS in the postconstruction period, it is difficult to consider the variable features of unsaturated-saturated loess strata, such as the underground water level decline, the dissipation of pore water pressure, the creep deformation of the surrounding soil, and the train vibration loading. The water seepage issues and the causes of the uneven settlement of the tunnel in Shanghai Metro lines 1 and 2 have been widely investigated and reported. In addition, the SS that has been induced by the additional load, the underground construction, and fall of the ground water level has also been studied by Shen et al. [23-27]. Ng et al. [28] summarized the settlement measurements of Shanghai Metro line 1 from 1994 to 2007, and the relationship between ground pumping, foundation soil compression, and the tunnel settlement has been reported. Soga et al. [29] studied the tunnel deformation caused by the dissipation of excess pore water pressure of the soil and the aging of grouting materials after lining segments in the London subway. A theory for calculating the SS has been proposed, which considers the interactions between the soil and the lining. Based on dynamic load testing, the critical dynamic stress ratio and the dynamic stress amplitude of saturated loess were proposed by Cui [30]; and the SS caused by the subway vibration loading has been calculated.

In addition, the surface settlement induced by freezing construction is becoming a trending issue in the freeze-thaw zone. Zhou et al. [31] and Shen et al. [23] studied the pathdependent mechanical behaviours of frozen loess based on the experimental investigation. Zheng et al. [32] proposed a practical method to simulate and predict the ground surface deformation during the entire artificial ground freezing construction process. A model test system and numerical method were used by Cai et al. [33] to simulate horizontal ground freezing on the heaving displacement of twin tunnels. Zhou et al. [34] published a segregation potential model to predict the frost heaves during freezing construction.

From the above, valuable results have been reported on analytical methods for the SS induced by underground construction; however, there is still no systematic research to explore the influence degrees of different factors on the SS, which is essential for determining the prioritization of SS control measures. On the basis of summarizing previously reported analytical methods and taking the shield construction of the Xi'an Metro in the loess stratum as the research background, the calculation methods of surface settlement induced by nine factors were proposed, and a parametric sensitivity analysis of the maximum surface settlement (MSS) induced by each individual influence factor was conducted. The resulting sensitivity indexes are sorted in order to provide technical guidance for SS controls during the shield tunneling construction.

\section{Estimation of the Maximum Surface Settlement}

2.1. Maximum Settlement Estimation of the Tunnel Vault during the Construction Period. Due to the improper control of the shield excavation, the factors inducing the settlement of the tunnel vault mainly include (1) inadequate shield support pressure, (2) insufficient grout filling in the shield tail, (3) insufficient grouting pressure, (4) overexcavation by the shield yawing, and (5) improper shield attitude. The methods to calculate the volume loss of the stratum and the SS generated when the tunnel vault deformation is induced by these factors are summarized in the following.

2.1.1. Tunnel Vault Settlement Induced by Inadequate Shield Support Pressure. During the tunneling of the earth pressure-balanced shield machine, the shield support pressure $\left(P_{i}\right)$ plays a dynamic balancing role on the lateral soil pressure $\left(K_{0} P_{0}\right.$ or $\left.K_{0}^{\prime} P_{v}^{\prime}+P_{w}\right)$ at the excavation surface. When the lateral soil pressure between the shield head and the excavation surface is unbalanced, it inevitably leads to the ground uplift and settlement. When $P_{i}=K_{0} P_{0}$ (see Figure 1(a)), the lateral soil pressure is in an equilibrium state, and little additional stress occurs on the excavation surface. When the shield support pressure is lower than the lateral earth pressure $\left(P_{i}<K_{0} P_{0}\right.$, see Figure $\left.1(\mathrm{~b})\right)$, the tunnel vault settlement occurs. When the shield support pressure is higher than the lateral earth pressure $\left(P_{i}>K_{0} P_{0}\right.$, see Figure $1(\mathrm{c}))$, the tunnel vault and surface uplift. This principle is illustrated in Figure 1.

In order to determine the tunnel vault settlement induced by an inadequate shield support pressure under undrained conditions, Lee and Rowe [35] proposed a twodimensional analytical solution by considering the threedimensional elastic-plastic deformation at the excavation surface. The shield support pressure ratio $\beta=P_{i} /\left(K_{0}^{\prime} P_{v}^{\prime}+P_{w}\right)$ is introduced into the above solution, and the tunnel vault settlement $\left(u_{c 1}\right)$ formula can be written as follows:

$$
u_{c 1}=\frac{\Omega R\left(K_{0}^{\prime} P_{V}^{\prime}+P_{w}-P_{i}\right)}{2 E_{u}}=\frac{\Omega R(1-\beta)\left(K_{0}^{\prime} P_{V}^{\prime}+P_{w}\right)}{2 E_{u}},
$$

where $u_{c 1}$ is the tunnel vault settlement and $\Omega$ is the horizontal displacement coefficient at the shield excavation surface, which is determined by a $3 \mathrm{D}$ numerical simulation 

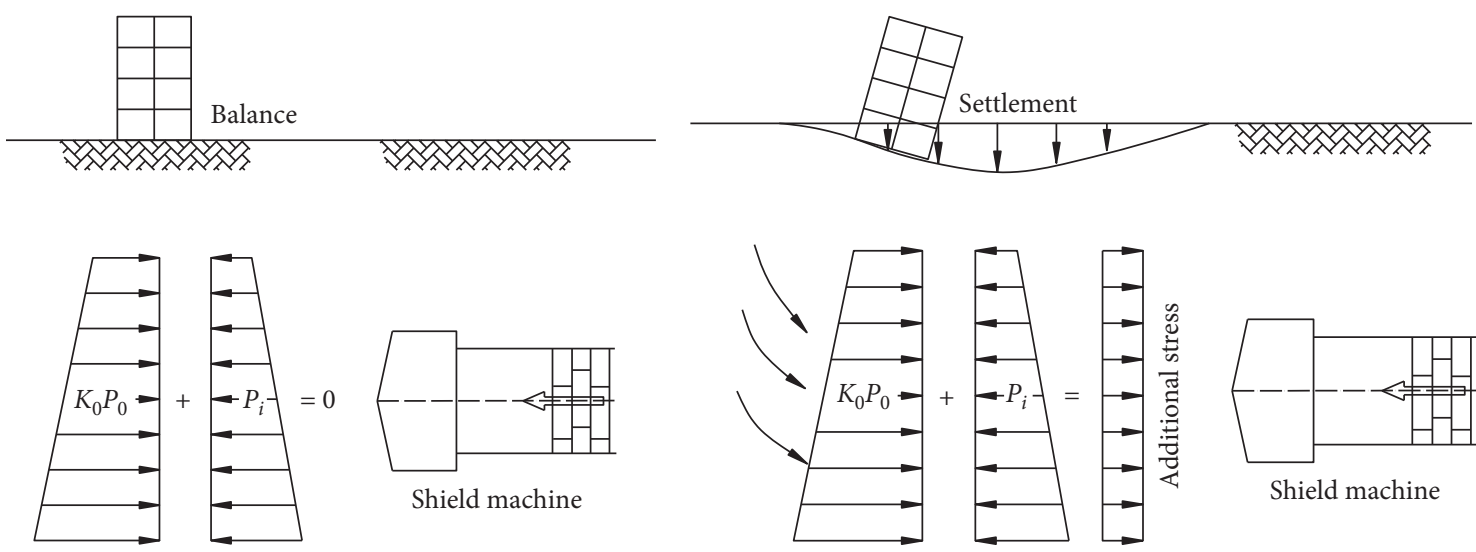

(a)

(b)
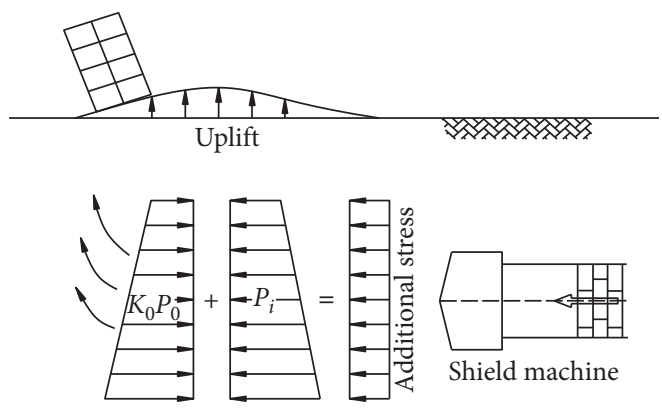

(c)

FIGURE 1: Surface movement behavior during the shield machine advancing. (a) $P_{i}=K_{0} P_{0}$. (b) $P_{i}<K_{0} P_{0}$. (c) $P_{i}>K_{0} P_{0}$.

of the shield tunnel excavation. In addition, $K_{0}$ is the coefficient of the lateral soil pressure in the tunnel; $P_{0}$ is the vertical soil pressure at the tunnel axis $(\mathrm{kPa}) ; K_{0}^{\prime}$ is the horizontal lateral pressure coefficient under the undrained condition; $P_{v}^{\prime}$ is the vertical effective stress $(\mathrm{kPa})$ at the tunnel axis; $P_{w}$ is the pore water pressure $(\mathrm{kPa})$ at the tunnel axis; $P_{i}$ is the support pressure of the shield chamber $(\mathrm{kPa}) ; R=D / 2$ is the tunnel excavation radius ( $\mathrm{m}) ; D$ is the shield excavation diameter $(\mathrm{m})$; and $E_{\mu}$ represents the undrained elastic modulus of the overlying soil stratum of the tunnel (MPa).

Liu [36] reported that, in reality, drained elastic modulus $E_{0}$ is 2.0 5.0 times larger than the compression modulus $E_{s}$. He suggested that the relationship between $E_{0}$ and $E_{s}$ could be a function of the initial void ratio $\left(e_{0}\right)$ in the loess stratum:

$$
E_{0}=\frac{2.718 E_{s}}{e_{0}} \text {. }
$$

According to elastic theory, the relationship between the undrained elastic modulus $E_{u}$ and the partially drained elastic modulus $E_{0}$ can be expressed as

$$
\frac{E_{u}}{E_{0}}=\frac{1+v_{u}}{1+v_{0}} .
$$

Therefore, by combining (2) and (3), the undrained elastic modulus can be written as

$$
E_{u}=\frac{2.718 E_{s}\left(1+v_{u}\right)}{\left(1+v_{0}\right) e_{0}}
$$

where $v_{u}=0.5$ is the undrained Poisson's ratio and $v_{0}$ is the drained Poisson's ratio. In the loess stratum, $v_{0}$ can be estimated using $\nu_{0}=K_{0} /\left(1+K_{0}\right)$, where $K_{0}$ is the coefficient of lateral stress at rest (and is equal to 1.0 under undrained conditions).

Based on the above theory, in shield tunneling construction, the undrained condition means that the soil around the tunnel will not be consolidated and drained during the rapid shield advancing. The soil element is in the uniform compression state, and the coefficient of lateral stress at rest is $K_{0}=1.0$; therefore, the undrained Poisson's ratio $v_{u}=K_{0} /\left(1+K_{0}\right)=1 / 2=0.5$.

2.1.2. Tunnel Vault Settlement Induced by Insufficient Grouting at the Shield Tail. During shield tunneling, for controlling the volume loss of the stratum, the grouting at the shield tail can be rapidly filled in the physical gap between the shield shell and the lining $G_{p}=2 \Delta+\delta$ [35], as illustrated in Figure 2. However, due to the lengthy operation time span, grouting losses can occur during transport, and the grouting volume can shrink and harden. As a result, the grouting cannot fully fill the gap. The soil behind the lining segments collapses, and the tunnel crown settlement occurs.

The settlement of the tunnel crown caused by insufficient grouting at the shield tail is

$$
u_{c 2}=(1-\omega) G_{p},
$$




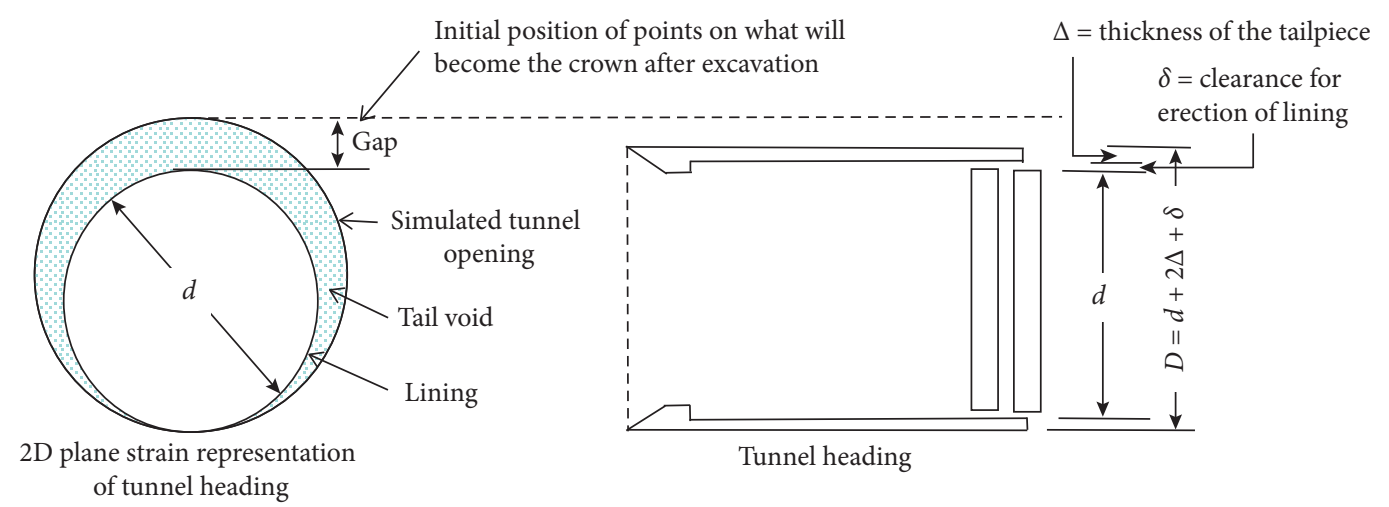

Figure 2: Gap of the shield tail (after Lee and Rowe [35]).

where the parameter $G_{p}$ is the shield physical gap (mm), $d$ is the outer diameter of the shield segment lining, $\Delta$ is the thickness of the shield tail appendages, $\delta$ is the lining assembling clearance, and $\omega$ is the grouting filling rate. The value of $\omega$ is controlled between 0.8 and 1.0; the average value of $\omega$ is between 0.90 and 0.95 when the shield control technology is rigorously applied.

\subsubsection{Tunnel Vault Settlement Induced by Insufficient} Grouting Pressure. As the shield tunnel advances, the synchronous grouting at the shield tail is mainly distributed in the range of $90 \sim 180^{\circ}$ around the lining arch ring. For a simple analysis, the grouting pressure $\left(P_{i l}\right)$ at the shield tail is distributed in the "crescent shape" as illustrated in Figure 3. In this way, when the grouting equipment fails or the grouting pressure is not balanced with the initial soil pressure, the soil around the tunnel is inevitably filled into the shield gap, and the volume loss of the stratum occurs. When $P_{i l}<P_{v}$ (see Figure 3(a)), the overlying soil stratum subsides; in contrast, when $P_{i l}>P_{v}$ (see Figure 3(b)), the surface uplifts (i.e., heaves). This principle is illustrated in Figure 3.

Rowe et al. [37] proposed the tunnel vault settlement is caused by an insufficient supporting force. This can be extended to the condition in which the grouting pressure is less than the tunnel vault settlement $\left(u_{c 3}\right)$. Because the grouting pressure $\left(P_{i l}\right)$ and the initial soil pressure $\left(P_{0}\right)$ are a pair of unbalanced forces, the grouting pressure ratio $\lambda=P_{i l} / P_{0}$ can be introduced to Rowe's formula to calculate the tunnel vault settlement under different grouting pressure ratios.

$$
u_{c 3}=\left(\frac{1}{3} \sim \frac{1}{4}\right) \times R\left[1-\sqrt{\frac{1}{1+\left(2\left(1+v_{u}\right) c_{u} / E_{u}\right)\left[\exp \left((1-\lambda) P_{0}-c_{u} / 2 c_{u}\right)\right]^{2}}}\right],
$$

where $E_{u}, c_{u}$, and $v_{u}$ are the undrained elastic modulus $(\mathrm{MPa})$, cohesive strength $(\mathrm{kPa})$, and Poisson's ratio of the overlying strata of the tunnel, respectively. $P_{0}$ is the vertical soil pressure of the tunnel axis; $P_{i l}$ is the average grouting pressure $(\mathrm{kPa})$ on the tunnel vault; and $P_{v}$ is the overburden pressure at the tunnel vault. According to the theory of Rowe et al. [37], the values of the coefficients $1 / 3$ and $1 / 4$ in equation (4) are set as follows: when the soil mass at the tunnel crown undergoes elastic deformation, the value is set to $1 / 3$; when the elastic-plastic deformation of the soil mass at the tunnel crown occurs, the value is set to $1 / 4$. The deformation pattern at the tunnel crown is determined by the stability coefficient of the excavation surface $N$, which has been introduced in Section 2.1.1.

2.1.4. Tunnel Vault Settlement Induced by Overexcavation. As the shield tunnel advances, the heterogeneity of the soil stratum leads to the shield snaking or yawing, causing an overexcavation of the shield. Suppose the radial maximum eccentricity is $\delta_{0}$, which can be calculated from the measured values of the horizontal eccentricity $S_{H}$ and vertical eccentricity $S_{V}$, and its eccentricity angle is $\alpha$. Then, the shaded area $\left(S_{e}\right)$ on the tunnel section is the overexcavation area. When the shield tunneling machine is corrected to the design axis, overexcavation inevitably occurs as illustrated in Figure 4. In order to calculate the volume loss of the overburden soil caused by overexcavation, the overexcavation area $\left(S_{e}\right)$ is equivalent to the "crescent" area of the arch. According to the gap parameter principle in Figure 2, the tunnel vault settlement $\left(u_{c 4}\right)$ caused by the overexcavation can be obtained:

$$
u_{c 4}=2\left(\sqrt{2 R^{2}\left(1-\frac{1}{\pi} \arccos \frac{\kappa L}{2 R}\right)+\frac{\kappa L}{2 \pi} \sqrt{4 R^{2}-\kappa^{2} L^{2}}}-R\right)
$$

where $\delta_{0}=\kappa L$ is the yawing distance of the shield head $(\mathrm{mm})$, $\kappa$ is the overexcavation rate, $\kappa=0.0 \%- \pm 2.0 \%$, and $L$ is the length of the shield tunneling machine (m). 


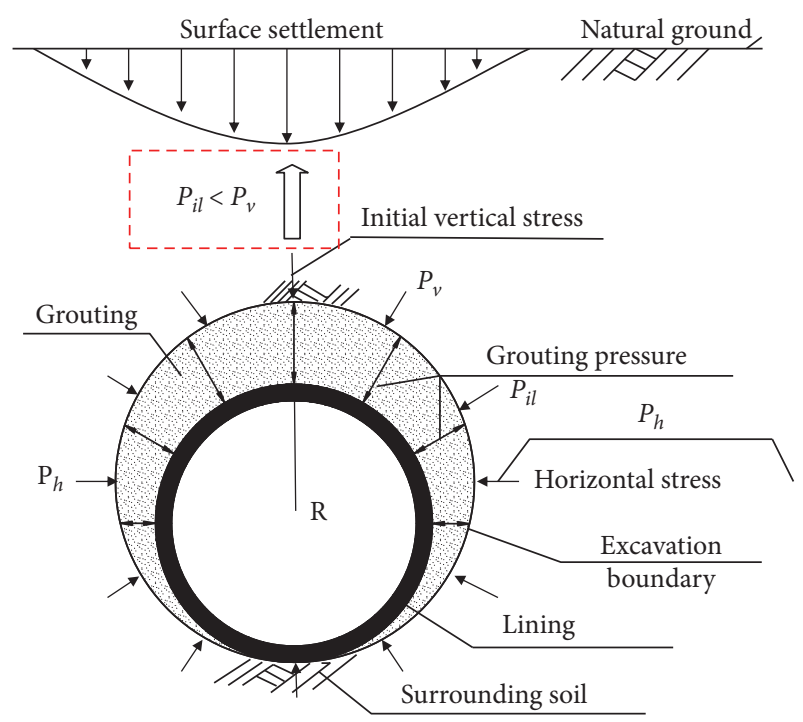

(a)
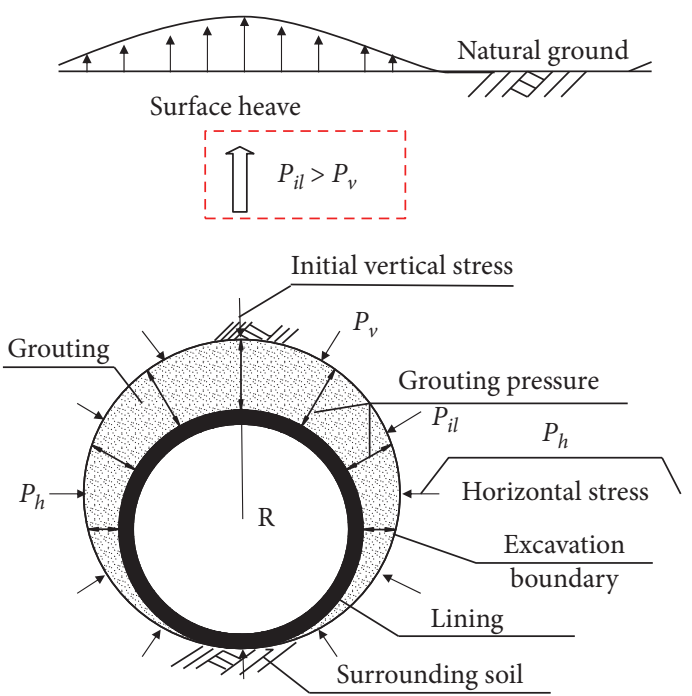

(b)

Figure 3: The surface movement during the shield tail grouting: (a) $P_{i l}<P_{v}$ and (b) $P_{i l}>P_{v}$.
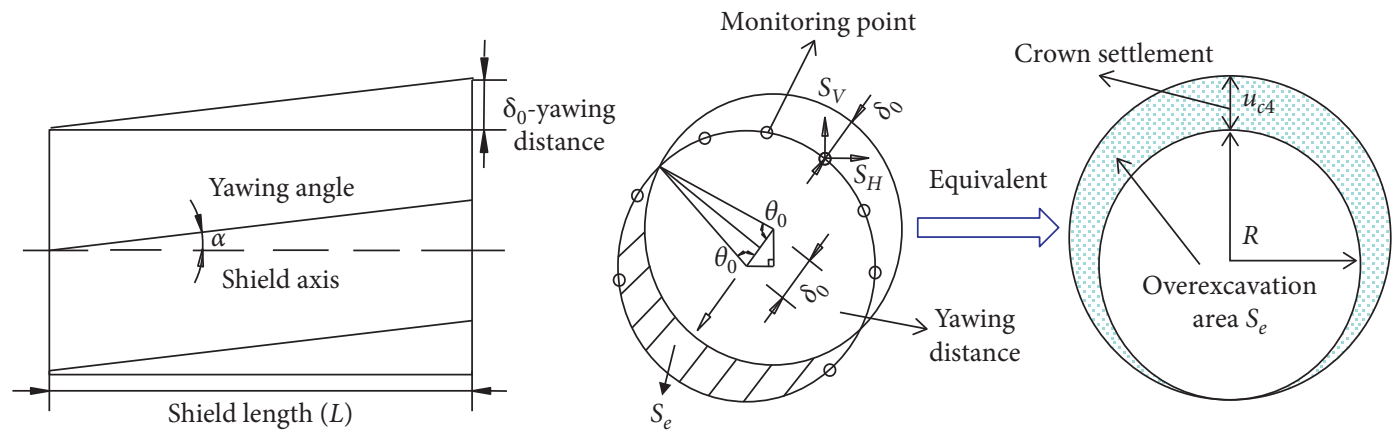

FIGURE 4: Tunnel vault deformation caused by shield overexcavation.

2.1.5. Tunnel Vault Settlement Induced by Improper Shield Attitude. As the shield tunneling advances, compression deformation occurs at the top or the bottom of the tunnel due to the failure of the tunneling system. The tunnel vault settlement $\left(u_{c 5}\right)$ caused by the head knocking and lifting of the shield tunneling machine is described as follows:

$$
u_{c 5}=L \xi
$$

where $\xi$ is the head knocking and lifting slope of the shield tunneling machine deviating from the central axis, generally, the term $\xi=-3.0 \% \sim+3.0 \%$, and $L$ is the length of the shield tunneling machine $(\mathrm{m})$.

\subsection{Estimation of the Surface Settlement during the Post-} construction Period. The SS caused by the shield tunnel advancing during the construction period can be strictly controlled within the allowed values according to construction experience. However, during the postconstruction period, the geological conditions change over time, which impacts the SS. These dynamic conditions include (1) the recompression of the soil in the loosened circle around the tunnel, (2) the dissipation of excess pore water pressure induced by the shield tunneling advancing, (3) the surrounding soil consolidation due to the failure of the waterproofing behind the lining and the underground water level decline, (4) the foundation settlement caused by the train vibration loading, etc.

2.2.1. Recompression Settlement of the Soil in the Loosened Circle. As the shield advances and cuts, the surrounding soil is disturbed and loosened due to the friction effect between this soil and the shield machine. This can lead to the plastic deformation and instability of the surrounding soil. The radius of the loosened circle is $R_{0}$, and the ratio of the loosened circle radius to the shield tunnel excavation radius is defined as $\eta=R_{0} / R$. Because of the recompression of the loosened soil around the tunnel, the uniform convergence deformation of the tunnel boundary is calculated as follows:

$$
\begin{aligned}
u_{p 1} & =m_{v}^{\prime}\left[\gamma\left(H-R_{0}\right)-P_{i l}\right]\left(R_{0}-R\right) \\
& =m_{v}^{\prime}(\eta-1) R\left[\gamma(H-\eta R)-P_{i l}\right],
\end{aligned}
$$


where $u_{p 1}$ is the uniform convergence deformation of the loosened soil circle; $H$ is the buried depth of the tunnel axis (m); $m_{v}^{\prime}$ is the soil volume compression coefficient of the loosened circle $\left(\mathrm{MPa}^{-1}\right)$, which is 3 5 times that of undisturbed soil; if considering the secondary grouting or strata pre-reinforcement effect, the volume compression coefficient of the soil $m_{v}^{\prime}$ is $0.2 \sim 1.0$ times that of undisturbed soil; and $R_{0}$ is the plastic zone radius of the loosened soil circle $(\mathrm{m})$, which is calculated as follows:

$$
R_{0}=R\left\{\frac{(1-\sin \varphi)\left[0.5\left(1+K_{0}\right) P_{0}-\left(1-K_{0}\right) P_{0}+c / \tan \varphi\right]}{P_{i l}+c / \tan \varphi}\right\}^{((1-\sin \varphi) / 2 \sin \varphi)}
$$

where $c$ and $\varphi$ are the cohesive force $(\mathrm{kPa})$ and the internal friction angle $\left({ }^{\circ}\right)$ of the soil mass, respectively, $K_{0}$ is the lateral pressure coefficient of the soil mass, and $P_{i l}$ is the grouting pressure $(\mathrm{kPa})$. If no measured data are available, $P_{i l}$ can be taken as the recommendation by Liu [36]:

$$
P_{i l}=(0.25-0.50) \frac{\gamma R[1+\tan (\pi / 4-\varphi / 2)]}{\tan \varphi} .
$$

Suppose the stratum volume loss $(V)$ due to the recompression of the soil in the loosened circle can be expressed as follows:

$$
V=\pi\left[R_{0}^{2}-\left(R_{0}-u_{p 1}\right)^{2}\right]
$$

Then, according to equation (7), the relationship among the total convergence deformations of the tunnel $\left(2 u_{p 1}\right)$, the MSS $\left(S_{p 1}\right)$, and the volume loss $(V)$ is

$$
\left\{\begin{array}{l}
2 u_{p 1}=\frac{V}{\sqrt{2 \pi} i_{z 1}}, \\
S_{p 1}=\frac{V}{\sqrt{2 \pi} i_{1}} .
\end{array}\right.
$$

The settlement trough width $\left(i_{z 1}\right)$ caused by soil recompression in the loosened circle during the postconstruction period is inconsistent with the surface settlement trough width $\left(i_{1}\right)$ during the construction period. According to experience [38], the relationship between $i_{z 1}$ and $i_{1}$ can be expressed as $i_{z 1}=\left(1-0.65 z_{1} / H\right) i_{1}$, where, $z_{1}=H-R_{0}$. Thus, $S_{p 1}$ induced by the recompression of the loosened circle can be written as

$$
S_{p 1}=2 u_{p 1}\left(1-0.65 \frac{z}{H}\right)=2 u_{p 1}\left[0.35+0.65 \frac{R_{0}}{H}\right] .
$$

\subsubsection{Consolidation Deformation Caused by the Dissipation} of Excess Pore Pressure. As the tunnel advances below the underground water level, when the thrust and friction of the shield tunneling machine and the grouting pressure are not balanced in the initial stress field, the additional load generates. Then, the soil within a certain range around the tunnel exhibits an excess pore pressure. It is assumed that the excess pore pressure at the tunnel crown is $P_{1}$, and the excess pore pressure at the ground surface is $P_{2}$. The underground water level is $d_{w}$ below the surface, and the vertical distance between the initial underground water level and the tunnel axis is $h_{w}$. According to the measurement, the distribution characteristics of the excess pore pressure around the tunnel are illustrated in the shaded part in Figure 5.

When the shield tunnel passes through the research region, the excess pore pressure gradually dissipates, and the consolidation deformation of the ground surface occurs. It can be calculated as follows [39]:

$$
S_{p 2}=\frac{\left(h_{w}-R\right) k_{y} t}{\sqrt{2 \pi} i_{2}}
$$

where $S_{p 2}$ is the SS value caused by the excess pore pressure dissipation; $k_{y}$ is the weighted average of the vertical permeability coefficient $(\mathrm{m} / \mathrm{d})$ of the overlying soil layers; $i_{2}$ is the settlement trough width; $h_{w}$ is the depth of the underground water level from the tunnel axis (m); and $t$ is the dissipation time of the excess pore pressure (d). The dissipation time is related to the average excess pore pressure $P$ and the average compression modulus $E_{s}$ of the soil skeleton as follows:

$$
t=\frac{\sqrt{2 \pi} k H P}{E_{s} k_{y}}
$$

When considering situations in which foundation reinforcement measures are taken, the term $E_{s}$ can be replaced with the composite foundation formula $E_{s p}=[1+m(n-1)] \alpha$ $E_{s}$, where $m$ is the replacement rate, $n$ is the pile-soil modulus ratio, and $\alpha$ is the compression modulus ratio between the piles and the soil. According to engineering experience, $E_{s p} \approx 1.5-6.0 E_{s}$; for saturated loess strata, the average value is $E_{s p}=4.0 E_{s}$.

When there are no measured data, the average additional pressure $(P)$ at the excavation surface is $P= \pm 20 \mathrm{kPa}$. The average excess pore pressure $\left(P=\left(P_{1}+P_{2}\right) / 2\right)$ in the saturated soil around the tunnel during shield tunnel advancing can also be approximately calculated by $\mathrm{Xu}$ [40].

(1) When $N=\left(K_{0}^{\prime} P_{v}^{\prime}+P_{w}-P_{i}\right) / c_{u}>0$,

$$
P=0.5 c_{\mathrm{u}}\left[(N+1+a \sqrt{6})+a \sqrt{6}\left(\frac{R}{H}\right)^{2} \exp (N-1)\right] \text {. }
$$

(2) When $N=\left(K_{0}^{\prime} P_{v}^{\prime}+P_{w}-P_{i}\right) / c_{u}<0$, 


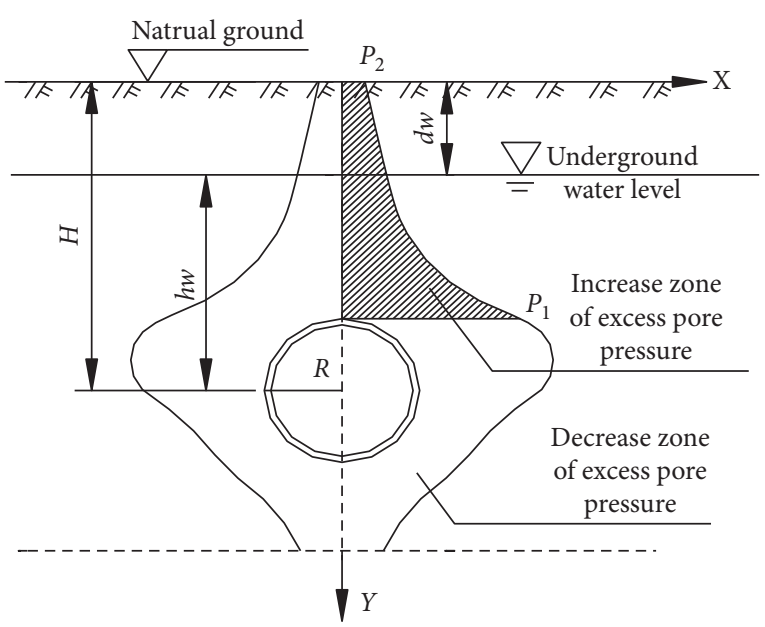

Figure 5: Distribution of excess pore water pressure.

$$
P=0.5 c_{u}\left[(a \sqrt{6}-N-1)+a \sqrt{6}\left(\frac{R}{H}\right)^{2} \exp (-N-1)\right]
$$

where $c_{u}$ is the undrained shear strength, $a$ is the Henkel coefficient, for saturated loess, $a=0.12$, and the other parameters have the same physical meaning as for (1). Now, assuming the excess pore pressure ratio $\psi=P / P_{0}$, the SS caused by the excess pore pressure dissipation is written as

$$
S_{p 2}=\frac{\left(h_{w}-R\right) P}{E_{s}}=\frac{\left(h_{w}-R\right) \psi P_{0}}{E_{s}} .
$$

2.2.3. Consolidation Deformation Caused by the Decline of the Underground Water Level. The underground water level declines when the drainage facilities of the underground structure of the shield tunnel fail, which leads to the longterm consolidation settlement of the ground surface. Suppose that the initial underground water level below the surface is $d_{w}$, and $H_{0}$ is the reference depth below the surface. The initial water level, the final water level, and the decline of the water level are $h_{1}, h_{2}$, and $\Delta h=h_{1}-h_{2}$, respectively. $E_{s 1}$ is the soil compression modulus after consolidation $(\mathrm{MPa})$, and $E_{s 2}$ is the compression modulus of the saturated soil $(\mathrm{MPa})$. The water level decline and the effective stress of soil changes are illustrated in Figure 6.

According to Figure 6, based on one-dimensional consolidation theory, the consolidation deformation $\left(S_{1}\right)$ caused by the water level decline within the scope of $\Delta h$ and the compression deformation $\left(S_{2}\right)$ caused by the increase of the effective stress within the scope of $h_{2}$ can be calculated as follows:

$$
\left\{\begin{array}{l}
S_{1}=\frac{0.5 \gamma_{w} \Delta h^{2}}{E_{s 1}}, \\
S_{2}=\frac{\gamma_{w} \Delta h\left(H_{0}-\Delta h-d_{w}\right)}{E_{s 2}} .
\end{array}\right.
$$

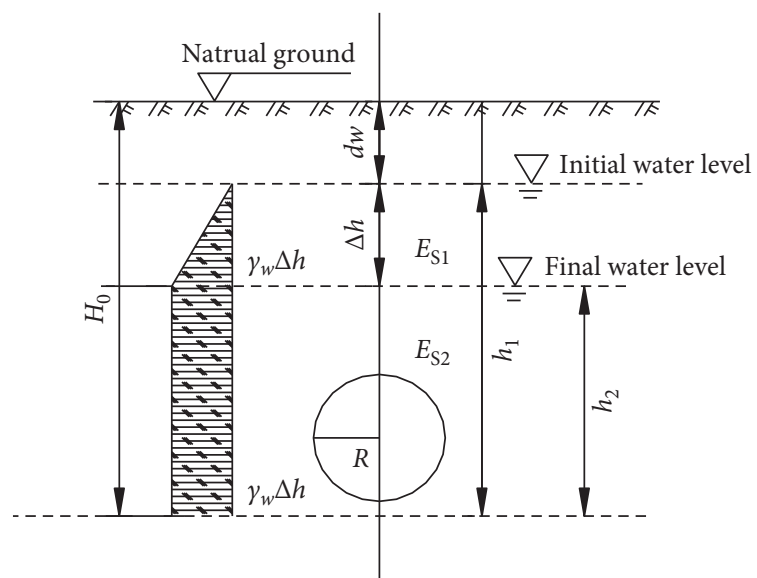

Figure 6: Additional stress caused by the decline of the underground water level.

Assume that the average densities of loess strata and pore water are $\gamma_{l}=19 \mathrm{kN} / \mathrm{m}^{3}$ and $\gamma_{w}=9.8 \mathrm{kN} / \mathrm{m}^{3}$, respectively, and $H_{0}$ is the calculation depth of the additional stress due to the water level decline. According to the theory of soil mechanics, suppose that $\gamma_{w} \Delta h=0.2 \gamma_{l} H_{0}$ and the term $H_{0}$ is approximately equal to $3 \Delta h$; then, the total consolidation settlement $\left(u_{p 3}\right)$ at the initial water level caused by the water level decline is

$$
u_{p 3}=\zeta \gamma_{w} \Delta h\left[\frac{\Delta h}{2 E_{s 1}}+\frac{2 \Delta h-d_{w}}{E_{s 2}}\right] .
$$

When $2 \Delta h-d_{w} \leq 0$, take $2 \Delta h-d_{w}=0$; when $\Delta h>h_{w}+R$, take $\Delta h=h_{w}+R$. If there are no measured values, the term $E_{s 1}$ is equal to $1.2 E_{s 2}$. $\zeta$ is the settlement adjustment coefficient, which considers the loess structural and hardening effect after the water loss in the loess; the term $\zeta=0.3$ is used in the saturated loess area. The decline in the ratio of the water level can be defined as $\theta=\Delta h / h_{w}$, while equation (21) can be expressed as a function of $\theta$ as follows:

$$
u_{p 3}=\zeta \gamma_{w} \Delta h\left[\frac{\theta h_{w}}{2 E_{s 1}}+\frac{(2 \theta+1) h_{w}-H}{E_{s 2}}\right] .
$$

Assume that the stratum volume loss $(V)$ due to the consolidation settlement is equal to $2 R u_{p 3}$, while the relationship among the maximum SS $\left(S_{p 3}\right), u_{p 3}$, and $V$ can be expressed as follows:

$$
\left\{\begin{array}{l}
u_{p 3}=\frac{V}{\sqrt{2 \pi} i_{z 3}}, \\
S_{p 3}=\frac{V}{\sqrt{2 \pi} i_{3}} .
\end{array}\right.
$$

According to the theory proposed by Han [38], the relationship between the deep layer settlement trough width $\left(i_{z 3}\right)$ and the surface settlement trough width $\left(i_{3}\right)$ can be written as $i_{z 3}=\left(1-0.65 z_{3} / H\right) i_{3}$, and the term $z_{3}=d_{w}$. Based on the above principles, the MSS value of $S_{p 3}$ caused by consolidation can be obtained as follows: 


$$
S_{p 3}=\frac{i_{z 3}}{i_{3}} u_{p 3}=u_{p 3}\left(1-0.65 \frac{d_{w}}{H}\right) .
$$

2.2.4. Seismic Surface Settlement Caused by the Train Vibration Loading. During the operational period of the subway, the large and medium pores of saturated loess in the tunnel foundation collapse under the train vibration cyclic loading. This causes a certain fatigue damage and compaction phenomenon of the tunnel foundation, and the settlement of the overlying soil and tunnel occurs. Based on extensive dynamic triaxial cyclic testing of saturated loess strata of the Xi'an subway, Zhang [41] reported that the dynamic stress ratio $R_{d}=0.026 \sim 0.192$ when the vibration frequency $f=2.0 \mathrm{~Hz}$. In addition, the author reported the following empirical equation that relates the loess residual strain $\left(\varepsilon_{s}^{c}\right)$ and $R_{d}$ :

$$
\varepsilon_{s}^{c}=2 c R_{d}^{m} \frac{\arctan \left(202.44 R_{d}^{m}\right)}{\pi},
$$

where $c=0.333, m=1.259$, and $R_{d}=0.5 \sigma_{d} / \sigma_{3} ; \sigma_{d}$ is the amplitude of the dynamic stress $(\mathrm{kPa})$, and $\sigma_{3}$ is the initial confining pressure of the soil $(\mathrm{kPa})$.

According to the existing empirical analyses, the influence depth of the dynamic stress load $\left(h_{d}\right)$ is reported to as being between 3.0 and $5.0 \mathrm{~m}$ beneath the tunnel foundation. In this way, the seismic SS of the saturated loess under the tunnel foundation can be obtained. It should be noted that when the tunnel foundation is unsaturated loess, the seismic deformation does not exist. Based on the theory of stratum volume loss, the volume loss due to seismic deformation $(V)$ is equal to $2 R h_{d} \varepsilon_{s}^{c}$, and the seismic settlement at the tunnel crown can be obtained as follows:

$$
u_{p 4}=\frac{V}{\sqrt{2 \pi} i_{z 4}}=\frac{2 R h_{d} \varepsilon_{s}^{c}}{\sqrt{2 \pi} i_{z 4}}=\frac{0.51 c R R_{d}^{m} \arctan \left(202.44 R_{d}^{m}\right) h_{d}}{i_{z 4}},
$$

where $i_{z 4}$ is the width of the settlement trough at depth $z_{4}=H-R ; i_{4}$ is the width of the surface settlement trough caused by the seismic settlement. According to the theory proposed by Han [38], $\left.i_{z 4}=[1-0.65(H-R) / H)\right] i_{4}$. The MSS of $S_{p 4}$ caused by the train vibration loading can be written as follows:

$$
S_{p 4}=\frac{i_{z 4}}{i_{4}} u_{p 4}=u_{p 4}\left(1-0.65 \frac{H-R}{H}\right)=u_{p 4}\left(0.35+0.65 \frac{R}{H}\right) .
$$

\subsection{Modified Peck Curve of the Surface Settlement Trough}

2.3.1. Surface Settlement Prediction during the Construction Period. It is assumed that the convergence form of tunnel sections is "crescent" shaped, as shown in Figure 2, and the volume loss caused by the convergence of tunnel sections beneath undrained conditions during the shield tunnel construction is equal to that caused by the SS. According to the concept of volume loss [12] and the Peck formula [42], the MSS during the shield construction period under different influencing factors can be estimated. The relationship among $S_{c}$, volume loss $\left(V_{l}\right)$, surface settlement trough width $(i)$, shield tunnel excavation radius $(R)$, and tunnel vault settlement $\left(u_{c}\right)$ during the construction period is written as follows:

$$
S_{c}=\frac{V_{l} \pi R^{2}}{\sqrt{2 \pi} i}=\frac{\pi R^{2}\left(4 u_{c} R+u_{c}^{2}\right)}{4 R^{2} \sqrt{2 \pi} i}=\frac{0.313\left(4 u_{c} R+u_{c}^{2}\right)}{i} .
$$

By taking the aforementioned five influencing factors into consideration, the estimated expressions of the cumulative MSS $\left(S_{c}\right)$ and the cumulative tunnel vault settlement $\left(u_{c}\right)$ during the construction period can be obtained as follows:

$$
\left\{\begin{array}{l}
S_{c}=\sum_{j=1}^{5} S_{c j}, \\
u_{c}=\sum_{j=1}^{5} u_{c j},
\end{array}\right.
$$

where $S_{c j}$ and $u_{c j}$ are the MSS value and the tunnel vault settlement during the construction period, respectively; $j=1 \sim 5$ is the number of influencing factors; and $i$ is the SS trough width (m). Based on reported experiences, the SS trough width $i=k H$, where $k$ is the coefficient of the SS trough width.

The formula for estimating the SS trough curve $\left(S_{x c}\right)$ during the construction period can be obtained by integrating the aforementioned five factors (the five factors are shown in Section 2.1, which are the settlement induced by inadequate shield support pressure, the settlement induced by insufficient grouting at the shield tail, the settlement induced by insufficient grouting pressure, the settlement induced by overexcavation of the shield, and the settlement induced by improper shield attitude, respectively.) as follows:

$$
S_{x c}=S_{c}\left[\frac{-x^{2}}{2 i^{2}}\right]
$$

where $x$ is the horizontal distance between the surface point and the tunnel axis (m).

2.3.2. Surface Settlement Trough Prediction during the Postconstruction Period. Based on Peck's formula [42], the SS during the postconstruction period by considering the above four influencing factors (the four factors are shown in Section 2.2, which are the recompression settlement of the soil in the loosened circle, the consolidation deformation caused by the dissipation of excess pore pressure, the consolidation deformation caused by the decline of the underground water level, and the seismic SS caused by the train vibration loading, respectively) can be obtained as follows: 
TABLE 1: Physical and mechanics parameters of the tunnel's surrounding soils.

\begin{tabular}{lccccccccccc}
\hline Soil types & $w(\%)$ & $\begin{array}{c}\gamma_{d} \\
\left(\mathrm{kN} / \mathrm{m}^{3}\right)\end{array}$ & $e_{0}$ & $\begin{array}{c}c^{\prime} \\
(\mathrm{kPa})\end{array}$ & $\varphi^{\prime}\left(^{\circ}\right)$ & $\begin{array}{c}c_{u} \\
(\mathrm{kPa})\end{array}$ & $K_{0}^{\prime}$ & $\begin{array}{c}K_{20} \times 10^{-5} \\
(\mathrm{~cm} / \mathrm{s})\end{array}$ & $\begin{array}{c}C_{v} \\
\left(10^{-3} \mathrm{~cm}^{2} / \mathrm{s}\right)\end{array}$ & $\begin{array}{c}E_{s} \\
(\mathrm{MPa})\end{array}$ & $\begin{array}{c}m_{v}^{\prime} \\
(\mathrm{MPa})\end{array}$ \\
\hline $\begin{array}{l}\text { Miscellaneous } \\
\text { fill }\end{array}$ & 22.5 & 14.8 & 0.84 & - & - & - & - & - & - & 5.6 & 0.54 \\
Plain fill & $23.8-25.8$ & $13.9-14.8$ & $0.86-0.96$ & - & - & 15 & 0.70 & - & - & $5.3-6.0$ & $0.5-0.7$ \\
New loess & $24.6-25.4$ & $14.9-15.5$ & $0.76-0.83$ & $35-36$ & $24.1-26.0$ & $20-24$ & $0.65-0.63$ & $1.2-3.5$ & $1.09-2.16$ & $6.8-7.6$ & $0.39-0.44$ \\
Saturated loess & 25.5 & 15.7 & 0.78 & 35 & 22.2 & 26 & - & - & - & 6.0 & 0.50 \\
Ancient soil & $22.8-24.9$ & $15.8-16.4$ & $0.66-0.73$ & 40 & $25.0-26.7$ & $25-26$ & $0.62-0.64$ & 2.92 & 0.96 & $5.8-7.2$ & $0.42-0.52$ \\
Old loess & $22.8-23.9$ & $16.0-16.4$ & $0.66-0.70$ & $32-46$ & $20.1-26.4$ & $22-30$ & $0.60-0.69$ & $0.42-6.1$ & $0.12-2.19$ & $6.9-7.1$ & $0.40-0.42$ \\
Silty clay & $22.0-22.5$ & $16.4-16.6$ & $0.64-0.66$ & $42-50$ & $27.3-29.3$ & $23-35$ & $0.59-0.61$ & $0.01-1.4$ & $1.06-1.92$ & $7.2-7.8$ & $0.38-0.42$ \\
\hline
\end{tabular}

Note: the physical meaning of the parameters is, namely, $w$ : water content, $\gamma_{d}$ : dry bulk density, $E_{s}$ : compression modulus, $e_{0}$ : pore ratio, $c^{\prime}$ and $\varphi^{\prime}:$ index of effective shear strength, $m_{v}^{\prime}$ : compression coefficient of remorphic loess in the disturbed area, $K_{0}^{\prime}$ : side pressure coefficient, $K_{20}$ : permeability coefficient, and $C_{v}$ : consolidation coefficient under nondrainage conditions.

$$
S_{x p}=S_{p 1}\left[\frac{-x^{2}}{2 i_{1}^{2}}\right]+S_{p 2}\left[\frac{-x^{2}}{2 i_{2}^{2}}\right]+S_{p 3}\left[\frac{-x^{2}}{2 i_{3}^{2}}\right]+S_{p 4}\left[\frac{-x^{2}}{2 i_{4}^{2}}\right]
$$

where $i_{1}, i_{2}, i_{3}$, and $i_{4}$ are the width of the SS trough under different influencing factors during the postconstruction period.

2.3.3. Total Surface Settlement Trough Prediction. According to the SS characteristics during the construction period and the postconstruction period, the estimating formula for the SS curve with consideration of the above nine influencing factors based on Peck's formula is obtained as follows:

$$
\begin{aligned}
S_{x}= & S_{x c}+S_{x p}=S_{c}\left[\frac{-x^{2}}{2 i^{2}}\right]+S_{p 1}\left[\frac{-x^{2}}{2 i_{1}^{2}}\right]+S_{p 2}\left[\frac{-x^{2}}{2 i_{2}^{2}}\right] \\
& +S_{p 3}\left[\frac{-x^{2}}{2 i_{3}^{2}}\right]+S_{p 4}\left[\frac{-x^{2}}{2 i_{4}^{2}}\right] .
\end{aligned}
$$

\section{Sensitivity Analysis of the MSS Inducement}

3.1. Determination of the Influencing Factors. In order to further explore the nine factors (shield support pressure ratio $\beta$, grouting filling rate $\omega$, grouting pressure ratio $\lambda$, overexcavation rate $\kappa$, slope of the shield tunneling machine deviating from the central axis $\xi$, the ratio of the loosened circle radius $\eta$, excess pore pressure ratio $\psi$, decline in the ratio of the water level $\theta$, and dynamic stress ratio $R_{d}$ ) with respect to their influence degree of the MSS, it is necessary to carry out a single-factor sensitivity analysis. For this study, Xi'an Metro line 2 is taken as the engineering background, and the soil stratum of the tunnel is described as follows: (1) miscellaneous fill $(0.5 \sim 12.0 \mathrm{~m})$, (2) plain fill $(0.0 \sim 12.0 \mathrm{~m})$, (3) new loess $(0.0 \sim 9.0 \mathrm{~m}),(4)$ saturated loess $(0.0 \sim 5.0 \mathrm{~m}),(5)$ ancient soil $(2.0 \sim 5.0 \mathrm{~m}),(6)$ old loess $(3.0 \sim 6.0 \mathrm{~m})$, and $(7)$ silty clay (more than $20 \mathrm{~m}$ ). The underground water level is 9 12 $\mathrm{m}$ below the ground surface, and the tunnel vault is approximately $1 \sim 8 \mathrm{~m}$ below the underground water level. The shield tunnel crosses the silty clay layer, and above the tunnel crown is the saturated loess. The physical indexes and mechanical parameters of the soil stratum are presented in Table 1 [43].

The tunnel axis of Xi'an Metro line 2 is buried 14 22 $\mathrm{m}$ below the ground surface, with an average of $H=19 \mathrm{~m}$, the tunnel excavation diameter is $D=6.2 \mathrm{~m}$, the length of the shield tunneling machine $L=8.68 \mathrm{~m}$, the physical gap of the shield tunneling machine is $G_{p}=160 \mathrm{~mm}$, the control standards for the overexcavation rate are $\kappa=-2.0 \% \sim+2.0 \%$, and the slope of the shield tunneling machine deviating from the central axis is $\xi=-3.0 \% \sim+3.0 \%$. According to the engineering experiences of the Xi'an Metro, the variation range of the aforementioned influencing factors and other calculation parameters can be determined; these are presented in Table 2.

3.2. Determination and Analysis of the Sensitivity Index. In order to accurately describe the influence degree of various factors on the MSS, the sensitivity coefficient $(M)$ is introduced. The sensitivity index of a certain factor $(F)$ to the MSS is $M_{F}$ :

$$
M_{F}=\frac{(\Delta S / S)}{\Delta F / F},
$$

where $\Delta S$ is the difference between the MSS of a certain influencing factor and its reference value $F, S$ is the MSS under the reference influencing factor, $\Delta S / S$ is the variation ratio of the MSS, $F$ is the reference value of the influencing factor, $\Delta F$ is the variation of the influencing factor $F$, and $\Delta F /$ $F$ is the variation rate of the influencing factor. When $M_{F}>0$, it means that the MSS is positively correlated with the influencing factor $F$; when $M_{F}<0$, it means that the MSS is inversely related to the influencing factor $F$.

According to formula (33), the sensitivity coefficients of the nine factors mentioned above are defined as follows: $M_{\beta}$, $M_{\omega}, M_{\lambda}, M_{\kappa}, M_{\xi}, M_{\eta}, M_{\psi}, M_{\theta}$, and $M_{R} d$; these factors can be calculated according to formulas (34) to (42) in Table 3.

Based on equation (32) and Table 2, the calculated MSS and the average sensitivity indexes with different influencing factors are presented in Figure 7. The curves of $\Delta S / S$ and $\Delta F /$ $F$ are illustrated in Figure 8.

From Figures 7 and 8, it can be seen that 
TABLE 2: Numerical analysis schemes for a single factor.

\begin{tabular}{lcccccc}
\hline $\begin{array}{l}\text { Influencing } \\
\text { factors }\end{array}$ & \multicolumn{5}{c}{ Parameter's range } & Calculate required parameters \\
\hline$\beta$ & 0.3 & 0.4 & 0.5 & 0.8 & 0.9 & $H=19 \mathrm{~m}, R=D / 2=3.1 \mathrm{~m}, G_{p}=160 \mathrm{~mm}, i=8.17 \mathrm{~m}$ \\
$\omega$ & 0.8 & 0.85 & 0.9 & 0.95 & 0.99 & $E_{s 1}=6.6 \mathrm{MPa}, E_{s 2}=5.5 \mathrm{MPa}, E_{u}=25.6 \mathrm{MPa}, e_{0}=0.76, v_{u}=0.50, v_{0}=0.39, \gamma=19 \mathrm{kN} /$ \\
$\lambda$ & 0.5 & 0.7 & 0.9 & 1.0 & 1.2 & $\mathrm{~m}^{3}, K_{0}^{\prime}=0.64$ \\
$\kappa$ & $0.1 \%$ & $0.5 \%$ & $1.0 \%$ & $1.5 \%$ & $2.0 \%$ & $c_{u}=20.9 \mathrm{kPa}, c^{\prime}=35.5 \mathrm{kPa}, \varphi^{\prime}=24.4^{\circ}$ \\
$\xi$ & $0.1 \%$ & $0.8 \%$ & $1.5 \%$ & $2.5 \%$ & $3.0 \%$ & $P_{0}=\gamma H-P_{w}=281 \mathrm{kPa}, P_{w}=80.0 \mathrm{kPa}$ \\
$\eta$ & 1.01 & 1.05 & 1.1 & 1.2 & 1.5 & $P_{v}=\gamma\left(H-h_{w}\right)+\gamma^{\prime}\left(h_{w}-R\right)=253.1 \mathrm{kPa}, K_{0}^{\prime} P_{v}^{\prime}+P_{w}=242 \mathrm{kPa}$ \\
$\psi$ & 0.02 & 0.07 & 0.14 & 0.21 & 0.28 & $h_{w}=8.0 \mathrm{~m}$, when $\Delta h \leq 0.5\left(H-h_{w}\right), \Delta h=0.5\left(H-h_{w}\right)=5.5 \mathrm{~m}$, and $\Delta h \leq R+h_{w}=11.1 \mathrm{~m}$ \\
$\theta$ & 0.69 & 0.94 & 1.19 & 1.31 & 1.38 & $h_{d}=3 \mathrm{~m}$ \\
$R_{d}$ & 0.03 & 0.08 & 0.113 & 0.16 & 0.2 & \\
\hline
\end{tabular}

TABLE 3: Sensitivity indexes of different influencing factors of the MSS.

\begin{tabular}{lccc}
\hline$M_{\beta}=\left(\Delta S_{c 1} / S_{c 1}\right) /(\Delta \beta / \beta)$ & $(34)$ & $M_{\eta}=\left(\Delta S_{p 1} / S_{p 1}\right) /(\Delta \eta / \eta)$ & $(39)$ \\
$M_{\omega}=\left(\Delta S_{c 2} / S_{c 2}\right) /(\Delta \omega / \omega)$ & $(35)$ & $M_{\psi}=\left(\Delta S_{p 2} / S_{p 2}\right) /(\Delta \psi / \psi)$ & $(40)$ \\
$M_{\lambda}=\left(\Delta S_{c 3} / S_{c 3}\right) /(\Delta \lambda / \lambda)$ & $(36)$ & $M_{\theta}=\left(\Delta S_{p 3} / S_{p 3}\right) /(\Delta \theta / \theta)$ & $(41)$ \\
$M_{\kappa}=\left(\Delta S_{c 4} / S_{c 4}\right) /(\Delta \kappa / \kappa)$ & $(37)$ & $M_{R d}=\left(\Delta S_{p 3} / S_{p 3}\right) /(\Delta R d / R d)$ \\
$M_{\xi}=\left(\Delta S_{c 5} / S_{c 5}\right) /(\Delta \xi / \xi)$ & $(38)$ & \\
\hline
\end{tabular}

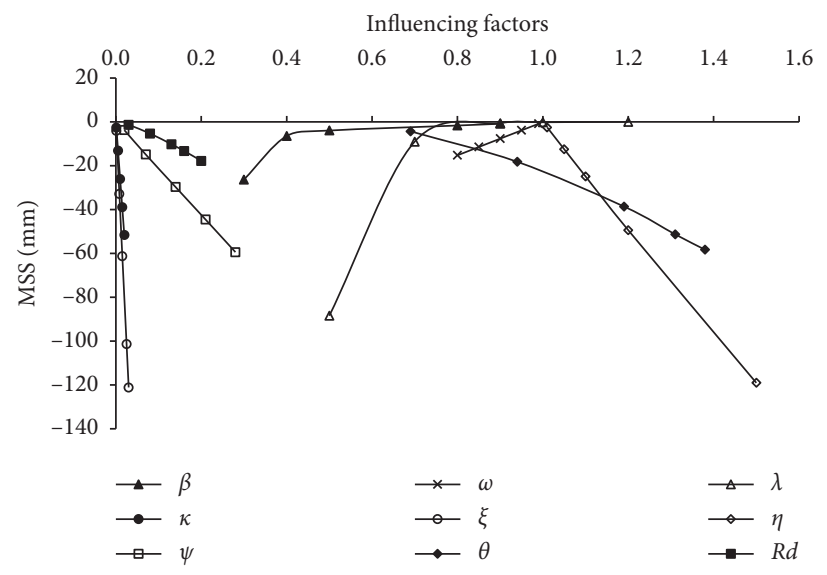

FIGURE 7: MSS values under different influencing factors.

(1) The MSS tends to decrease with the increase of $\beta, \omega$, and $\lambda$, indicating that the rate of change of these three influencing factors is inversely correlated with the change rate of the SS. Six influence factors (i.e., $\kappa$, $\eta, \xi, \psi, \theta$, and $R_{d}$ ) have positive relationships with the MSS.

(2) From the slope of the relationship curve between the incremental change rate of $(\Delta S / S)$ and the incremental change rate of influencing factors $(\Delta F / F)$, it shows that, during the construction period, the change of the grouting filling rate $(\omega)$ is the most sensitive influence factor to the MSS, followed by the grouting pressure ratio $(\lambda)$.

(3) During the postconstruction period, the ratio of the loosened circle radius $(\eta)$ has the most sensitive influence on the MSS, followed by the decline amount ratio of the water level $(\theta)$. It can be seen that the grouting effect of the shield tail and the disturbance degree to the surrounding soil during the construction period of shield tunneling have significant influence on the MSS.

(4) Table 3 shows that the average sensitivity index of the nine influencing factors can be ordered from highest to lowest, i.e., $M_{\eta}=98.97, M_{\theta}=11.20, M_{\omega}=4.00$, $M_{R d}=2.14, \quad M_{\lambda}=1.30, \quad M_{\beta}=1.15, \quad M_{\psi}=1.00$, $M_{\kappa}=0.99$, and $M_{\xi}=0.99$. This order shows that the disturbance degree to the surrounding soil during the shield tunnel advancing has the most significant influence on the MSS. When the declining ratio for the water level is high due to seepage of lining segments, the long-term SS during the postconstruction period is also significant. During the construction period of shield tunneling, the grouting filling effect and the control of grouting pressure have great influence on the SS. When the tunnel foundation and track are not reinforced, the SS 


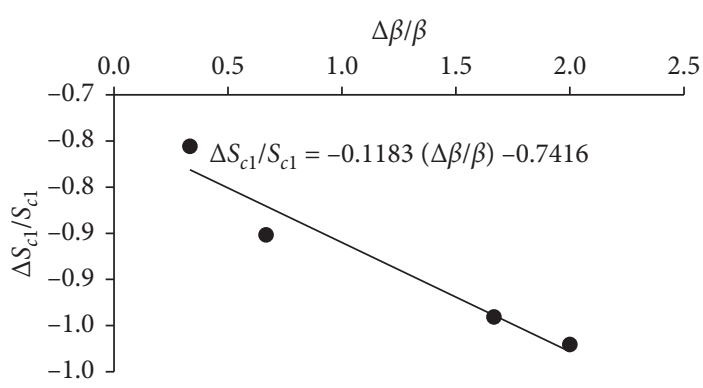

(a)

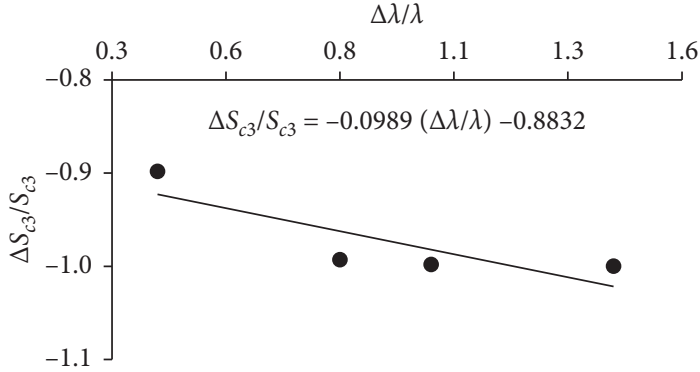

(c)

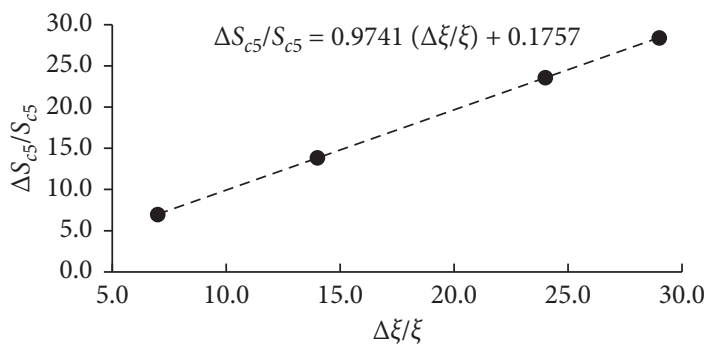

(e)

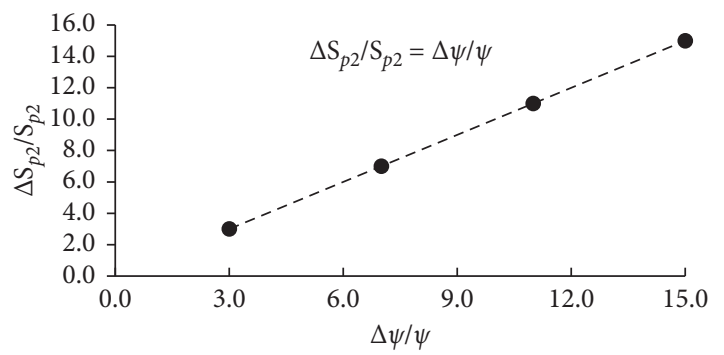

(g)

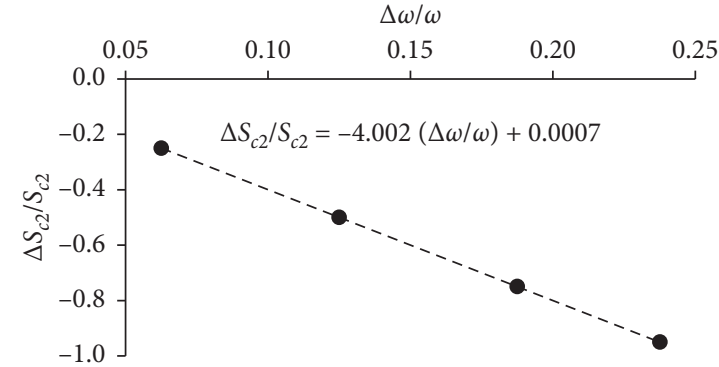

(b)

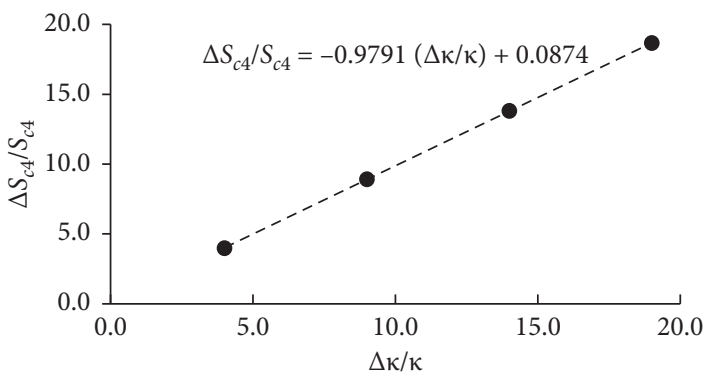

(d)

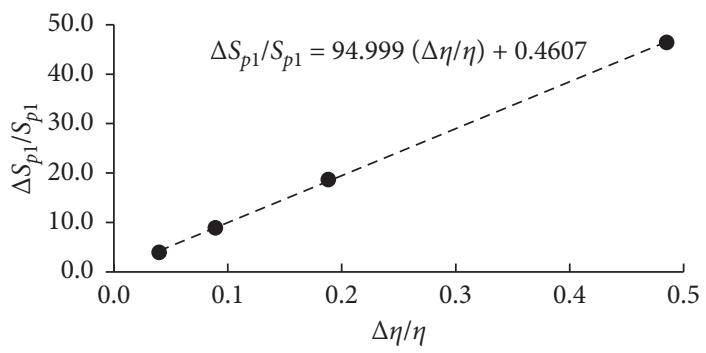

(f)

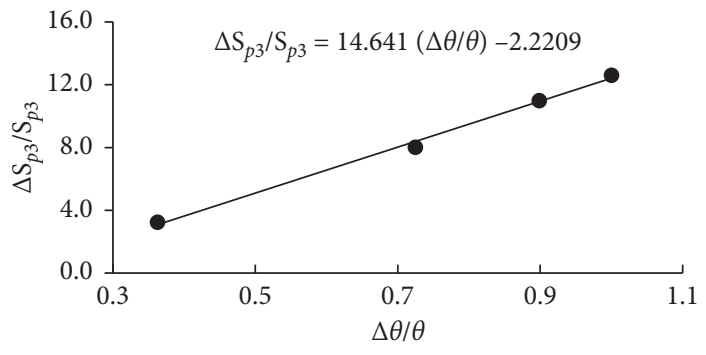

(h)

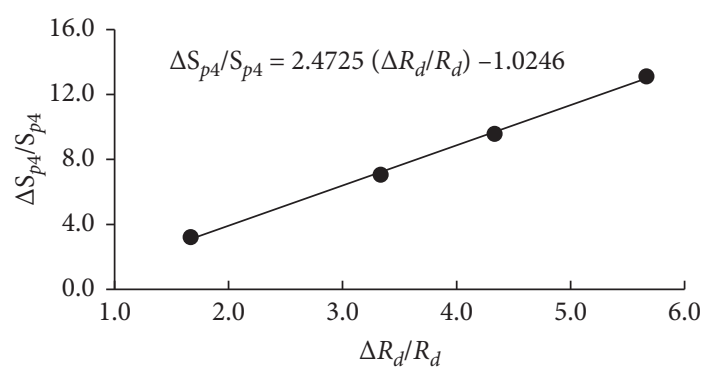

(i)

FIGURE 8: Relationship between the MSS ratio and the influencing factor ratios: (a) $\Delta S_{c 1} / S_{c 1}-\Delta \beta / \beta$, (b) $\Delta S_{c 2} / S_{c 2}-\Delta \omega / \omega$, (c) $\Delta S_{c 3} / S_{c 3}-\Delta \lambda / \lambda$, (d) $\Delta S_{c 4} /$ $S_{c 4}-\Delta \kappa / \kappa$, (e) $\Delta S_{c 5} / S_{c 5}-\Delta \xi / \xi$, (f) $\Delta S_{p 1} / S_{p 1}-\Delta \eta / \eta$, (g) $\Delta S_{p 2} / S_{p 2}-\Delta \psi / \psi, \Delta S_{p 3} / S_{p 3}-\Delta \theta / \theta$, and (i) $S_{p 4} / S_{p 4}-\Delta R_{d} / R_{d}$. 
caused by the train vibration loading cannot be ignored. The dissipation of the excess pore water pressure and the adjustment of the shield attitude are all related to the control technology during the construction period of shield tunneling.

\section{Conclusion}

(1) The SS during the construction period and the postconstruction period induced by the shield tunneling construction mainly includes nine influencing factors: (1) inadequate shield support pressure, (2) insufficient grouting filling in the shield tail, (3) insufficient grouting pressure, (4) overexcavation by shield yawing, (5) improper shield attitude, (6) the recompression of the soil in the loosing circle around the tunnel, (7) the dissipation of excess pore water pressure induced by the shield tunneling advancing, (8) the surrounding soil consolidation due to the failure of waterproofing techniques used behind the lining and the decline in the underground water level, and (9) the foundation settlement caused by the train vibration loading.

(2) The average sensitivity index of the above nine influencing factors can be ordered from highest to lowest: $M_{\eta}=98.97$ (the ratio of the loosened circle radius $\eta$ ), $M_{\theta}=11.20$ (decline in the ratio of the water level $\theta$ ), $M_{\omega}=4.00$ (grouting filling rate $\omega$ ), $M_{R d}=2.14$ (dynamic stress ratio $R d$ ), $M_{\lambda}=1.30$ (grouting pressure ratio $\lambda$ ), $M_{\beta}=1.15$ (shield support pressure ratio $\beta$ ), $M_{\psi}=1.00$ (excess pore pressure ratio $\psi$ ),$M_{\kappa}=0.99$ (overexcavation rate $\kappa$ ), and $M_{\xi}=0.99$ (slope of the shield machine deviating from the central axis $\xi$ ). It indicates that the largest influencing factor on surface settlement is the ratio of the loosened circle radius, and the smallest one is the slope of the shield tunneling machine deviating from the central axis.

(3) In summary, the disturbance degree of the surrounding soil during the shield tunnel advancing has the most significant influence on the MSS. The decline of the underground water level has the second largest influence on the SS. The grouting fill effect has the third greatest influence on the SS. The grouting pressure at the shield tail and the shield support pressure at the shield head have the fifth and sixth largest influences on the SS. When the tunnel foundation and the track are not reinforced, the SS caused by the train vibration loading cannot be ignored. The dissipation of the excess pore water pressure, overexcavation rate, and shield machine deviating from the central axis have the seventh, eighth, and ninth influence on the SS.

(4) When the shield tunnels pass through the saturated loess stratum, the disturbance degree on the surrounding soil during shield advancing should be well controlled. The pre-reinforcement measures for the saturated soil within $3 \sim 5 \mathrm{~m}$ around the tunnel should be taken, and the appropriate antiseepage and vibration reduction measures should be taken for the lining segments and the track, respectively.

\section{Data Availability}

No data, models, or code were generated or used during the study.

\section{Conflicts of Interest}

The author declares that there are no conflicts of interest.

\section{Acknowledgments}

The author would like to extend their gratitude to the National Natural Science Foundation of China (no. 51678484) and the Research Fund of the State Key Laboratory of Eco-hydraulics in Northwest Arid Region, Xi'an University of Technology (2019KJCXTD-12), who funded this research.

\section{References}

[1] C. Sagaseta, "Analysis of undraind soil deformation due to ground loss," Géotechnique, vol. 37, no. 3, pp. 301-320, 1987.

[2] A. Verruijt and J. R. Booker, "Surface settlements due to deformation of a tunnel in an elastic half plane," Géotechnique, vol. 46, no. 4, pp. 753-756, 1996.

[3] N. Loganathan and H. G. Poulos, "Analytical prediction for tunneling-induced ground movements in clays," Journal of Geotechnical and Geoenvironmental Engineering, vol. 124, no. 9, pp. 846-856, 1998.

[4] L.-Z. Wang, L.-L. Li, and X.-J. Lv, "Complex variable solutions for tunneling-induced ground movement," International Journal of Geomechanics, vol. 9, no. 2, pp. 63-72, 2009.

[5] J. Fu, J. Yang, L. Yan, and S. M. Abbas, "An analytical solution for deforming twin-parallel tunnels in an elastic half plane," International Journal for Numerical and Analytical Methods in Geomechanics, vol. 39, no. 5, pp. 524-538, 2015.

[6] A. Abbas, "Drained and undrained response of deep tunnels subjected to far-field shear loading," Tunnelling and Underground Space Technology, vol. 25, no. 1, pp. 21-31, 2010.

[7] K. H. Park, "Elastic solution for tunneling-induced ground movements in clays," International Journal of Geomechanics, vol. 4, no. 4, pp. 310-318, 2004.

[8] L. Ding, L. Ma, H. Luo, M. Yu, and X. Wu, "Wavelet analysis for tunneling-induced ground settlement based on a stochastic model," Tunnelling and Underground Space Technology, vol. 26, no. 5, pp. 619-628, 2011.

[9] X. L. Yu and J. M. Wang, "Ground movement prediction for tunnels using simplified procedure," Tunnelling and Underground Space Technology, vol. 26, no. 3, pp. 462-471, 2011.

[10] D. Huang and B. Zeng, "Influence of double-o-tube shield rolling on soil deformation during tunneling," International Journal of Geomechanics, vol. 17, no. 11, Article ID 04017105, 2017.

[11] Z. Zhang, M. Huang, X. Xi et al., "Complex variable solutions for soil and liner deformation due to tunneling in clays," International Journal of Geomechanics, vol. 18, no. 7, Article ID 04018074, 2018.

[12] C. González and C. Sagaseta, "Patterns of soil deformations around tunnels. Application to the extension of Madrid 
Metro," Computers and Geotechnics, vol. 28, no. 6-7, pp. 445-468, 2001.

[13] A. Verruijt, "Deformations of an elastic half plane with a circular cavity," International Journal of Solids and Structures, vol. 35, no. 21, pp. 2795-2804, 1998.

[14] A. Verruijt and J. R. Booker, "Complex variable analysis of Mindlin's tunnel problem," in Proceedings of the Booker Memorial Symposium, Developments in Theoretical Geomechanics, pp. 3-22, Balkema, Rotterdam, Netherlands, 2000.

[15] A. Verruijt and O. E. Strack, "Buoyancy of tunnels in soft soils," Géotechnique, vol. 58, no. 6, pp. 513-515, 2008.

[16] J. Fu, J. Yang, H. Klapperich et al., "Analytical prediction of ground movements due to a nonuniform deforming tunnel," International Journal of Geomechanics, vol. 16, no. 4, Article ID 04015089, 2016.

[17] W.-I. Chou and A. Bobet, "Predictions of ground deformations in shallow tunnels in clay," Tunnelling and Underground Space Technology, vol. 17, no. 1, pp. 3-19, 2002.

[18] K.-H. Park, "Analytical solution for tunnelling-induced ground movement in clays," Tunnelling and Underground Space Technology, vol. 20, no. 3, pp. 249-261, 2005.

[19] J. F. Liu and H. Z. Zhang, "Semianalytical solution and parameters sensitivity analysis of shallow shield tunneling-induced ground settlement," Advances in Materials Science and Engineering, vol. 2017, Article ID 3748658, 8 pages, 2017.

[20] D. Lu, F. Kong, X. Du, C. Shen, Q. Gong, and P. Li, "A unified displacement function to analytically predict ground deformation of shallow tunnel," Tunnelling and Underground Space Technology, vol. 88, pp. 129-143, 2019.

[21] C. Shen and Z. Zhu, "Analytical method for evaluating the ground surface settlement caused by tail void grouting pressure in shield tunnel construction," Advances in Civil Engineering, vol. 2018, Article ID 3729143, 10 pages, 2018.

[22] Y.-S. Fang, C.-T. Wu, S.-F. Chen, and C. Liu, "An estimation of subsurface settlement due to shield tunneling," Tunnelling and Underground Space Technology, vol. 44, pp. 121-129, 2014.

[23] M. D. Shen, Z. W. Zhou, and S. J. Zhang, "Effect of stress path on mechanical behaviours of frozen subgrade soil," Road Materials and Pavement Design, vol. 2021, no. 8, pp. 1-30, 2020.

[24] S.-L. Shen, H.-N. Wu, Y.-J. Cui, and Z.-Y. Yin, "Long-term settlement behaviour of metro tunnels in the soft deposits of Shanghai," Tunnelling and Underground Space Technology, vol. 40, no. 1, pp. 309-323, 2014.

[25] Y.-S. Yin, L. Ma, Y.-J. Du, and S.-L. Shen, "Analysis of urbanisation-induced land subsidence in Shanghai," Natural Hazards, vol. 63, no. 2, pp. 1255-1267, 2012.

[26] H.-N. Shen, R.-Q. Huang, W.-J. Sun et al., "Leaking behavior of shield tunnels under the Huangpu River of Shanghai with induced hazards," Natural Hazards, vol. 70, no. 2, pp. 1115-1132, 2014.

[27] C.-Y. Shen, S.-L. Shen, J. Han, G.-L. Ye, and S. Horpibulsuk, "Hydrogeochemical environment of aquifer groundwater in Shanghai and potential hazards to underground infrastructures," Natural Hazards, vol. 78, no. 1, pp. 753-774, 2015.

[28] C. W. W. Ng, G. B. Liu, and Q. Li, "Investigation of the longterm tunnel settlement mechanisms of the first metro line in Shanghai," Canadian Geotechnical Journal, vol. 50, no. 6, pp. 674-684, 2013.

[29] K. Soga, R. G. Laver, and Z. Li, "Long-term tunnel behaviour and ground movements after tunnelling in clayey soils," Underground Space, vol. 2, no. 3, pp. 149-167, 2017.

[30] G. Q. Cui, Dynamic Constitutive Model for Saturated Loess and Deformation Analysis for Soil Around Subway
TunnelXi'an University of Architecture \& Technology, Xi'an, China, 2014.

[31] Z. W. Zhou, W. Ma, S. J. Zhang, Y. H. Mu, and G. Y. Li, "Experimental investigation of the path-dependent strength and deformation behaviours of frozen loess," Engineering Geology, vol. 265, Article ID 105449, 2020.

[32] L. Zheng, Y. Gao, Y. Zhou, T. Liu, and S. Tian, "A practical method for predicting ground surface deformation induced by the artificial ground freezing method," Computers and Geotechnics, vol. 130, Article ID 103925, 2021.

[33] H. Cai, S. Li, Y. Liang, Z. Yao, and H. Cheng, "Model test and numerical simulation of frost heave during twin-tunnel construction using artificial ground-freezing technique," Computers and Geotechnics, vol. 115, Article ID 103155, 2019.

[34] J. Zhou, W. Zhao, Y. Tang et al., "Practical prediction method on frost heave of soft clay in artificial ground freezing with field experiment," Tunnelling and Underground Space Technology, vol. 107, Article ID 103647, 2021.

[35] K. M. Lee and R. K. Rowe, "Settlement due to tunneling: Part II -Evaluation of a prediction technique," Canadian Geotechnical Journal, vol. 29, no. 5, pp. 941-954, 1992.

[36] Z. D. Liu, Mechanics and Engineering of Loess, Shanxi Science and Technique Publishing House, Xi'an, China, 1997.

[37] R. K. Rowe, K. Y. Lo, and G. J. Kack, "A method of estimating SS above tunnels constructed in soft ground," Canadian Geotechnical Journal, vol. 20, no. 8, pp. 11-22, 1983.

[38] X. Han, The Analysis and Prediction of Tunnelling-Induced Building Deformation, Xi'an University of Technology, Xi'an, China, 2006.

[39] J. Liu and X. Hou, Shield Tunneling, China Railway Press, Beijing, China, 1991.

[40] F. Xu, "The analysis of pore water pressure and ground settlement caused by shield tunneling and deep excavation in soft clay," Doctorial thesis, Tongji University, Shanghai, China, 1991.

[41] K. Zhang, Vibration and Settlement of Loess Due to Subway Moving Loads, Xi'an University of Architecture \& Technology, Xi'an, China, 2011.

[42] R. B. Peck, "Deep excavations and tunneling in soft ground," in Proceedings of the 7th International Conference on Soil Mechanics and Foundation Engineering, pp. 225-290, Balkema, Rotterdam, Netherlands, 1969.

[43] C. Zhu and N. Li, "Prediction and analysis of surface settlement due to shield tunneling for Xi'an Metro," Canadian Geotechnical Journal, vol. 54, no. 4, pp. 529-546, 2017.

[44] Zhang, Study on the Laws of Surface Settlement Induced by Shield Construction and Control Technology of Xian Subway TunnelXian University of Science and Technology, Xi'an, China, 2011. 